\title{
Intrathecal immunoglobulin A and $G$ antibodies to synapsin in a patient with limbic encephalitis
}

\section{OPEN}

Johannes Piepgras* Markus Höltje, PhD* Carolin Otto, MD Hendrik Harms, MD Annyesha Satapathy Fabrizia Cesca, PhD

Fabio Benfenati, MD

Daniel Gitler, PhD

Andreas Pich, PhD Johannes-Friedrich Zander, PhD

Gudrun Ahnert-Hilger, $\mathrm{PhD} \ddagger$

Klemens Ruprecht, MD $\ddagger$

Correspondence to Dr. Ruprecht:

klemens.ruprecht@charite.de or Dr. Ahnert-Hilger: gudrun.ahnert@charite.de

Supplemental data at Neurology.org/nn

\section{ABSTRACT}

Objective: To report on the identification of intrathecally synthesized immunoglobulin A (lgA) and immunoglobulin $\mathrm{G}$ (lgG) antibodies to synapsin, a synaptic vesicle-associated protein, in a patient with limbic encephalitis.

Methods: Methods included clinical characterization, indirect immunofluorescence, immunoprecipitation, mass spectrometry, immunoblots of wild-type and synapsin I/II/II knockout mice, and cell-based assays with synapsin la, lb, Ila, and Illb plasmids.

Results: A 69-year-old man presented with confusion, disorientation, seizures, and left hippocampal hyperintensities on MRI. CSF examinations revealed an intrathecal IgA and IgG synthesis. Except for IgG antibodies to voltage-gated potassium channels in CSF, screening for known neuronal autoantibodies in serum and CSF was negative. However, indirect immunofluorescence using the patient's CSF showed binding of IgA to mouse hippocampus, amygdala, and cerebellum. Immunoprecipitation with CSF IgA followed by mass spectrometry identified synapsin as autoantigenic target. Knockout tissues and cell-based assays confirmed that $\lg A$ and $\lg G$ in the patient's CSF and serum reacted with synapsin la, lb, and Ila. Calculation of antibody indices proved intrathecal synthesis of anti-synapsin lgA and IgG. The patient responded clinically to immunotherapy but developed left hippocampal atrophy. CSF IgA or IgG of the patient did not bind to live, unfixed, and nonpermeabilized mouse hippocampal neurons, compatible with synapsin being an intracellular antigen.

Conclusions: This report identifies isoforms of the synaptic vesicle-associated protein synapsin as targets of intrathecally produced lgA and lgG antibodies in a patient with limbic encephalitis. Future studies should clarify the prevalence and pathogenic relevance of anti-synapsin antibodies in limbic encephalitis. Neurol Neuroimmunol Neuroinflamm 2015;2:e169; doi: 10.1212/NXI.0000000000000169

\section{GLOSSARY}

$\mathbf{A} \mathbf{I}=$ antibody index $\mathbf{C B A}=$ cell-based assay; $\mathbf{I g A}=$ immunoglobulin $\mathbf{A} ; \mathbf{I g G}=$ immunoglobulin $\mathbf{G} ; \mathbf{V G K C}=$ voltage-gated potassium channels.

Limbic encephalitis is characterized by memory dysfunction, seizures, behavioral changes, and mesiotemporal involvement on imaging or neuropathologic studies, and is frequently associated with antibodies to neuronal autoantigens. ${ }^{1}$ We report on the identification of synapsin, a synaptic vesicle-associated protein, as an antigenic target of intrathecally synthesized immunoglobulin A ( $\operatorname{Ig} A)$ and immunoglobulin $G(\operatorname{Ig} G)$ in a patient with limbic encephalitis.

METHODS Standard protocol approvals, registrations, and patient consents. The study was approved by the institutional review board of Charité-Universitätsmedizin Berlin (EA1/083/15) and written informed consent was obtained from the patient reported in this study.

*J. Piepgras and M. Höltje contributed equally to this work.

¥G. Ahnert-Hilger and K. Ruprecht contributed equally to this work.

From the Department of Neurology (J.P., K.R.) and Institute for Integrative Neuroanatomy (M.H., J.-F.Z., G.A.-H.), Charité-Universitätsmedizin Berlin; St. Josefs-Krankenhaus Potsdam (C.O., H.H.), Germany; the Department of Neuroscience and Brain Technologies (A.S., F.C., F.B.), Istituto Italiano di Tecnologia, Genova, Italy; the Department of Physiology and Cell Biology (D.G.), Faculty of Health Sciences and Zlotowski Center for Neuroscience, Ben-Gurion University of the Negev, Beer-Sheva, Israel; and the Institute of Toxicology (A.P.), Hannover Medical School, Germany.

Funding information and disclosures are provided at the end of the article. Go to Neurology.org/nn for full disclosure forms. The Article Processing Charge was paid by the authors.

This is an open access article distributed under the terms of the Creative Commons Attribution-NonCommercial-NoDerivatives License 4.0 (CC BY-NC-ND), which permits downloading and sharing the work provided it is properly cited. The work cannot be changed in any way or used commercially. 

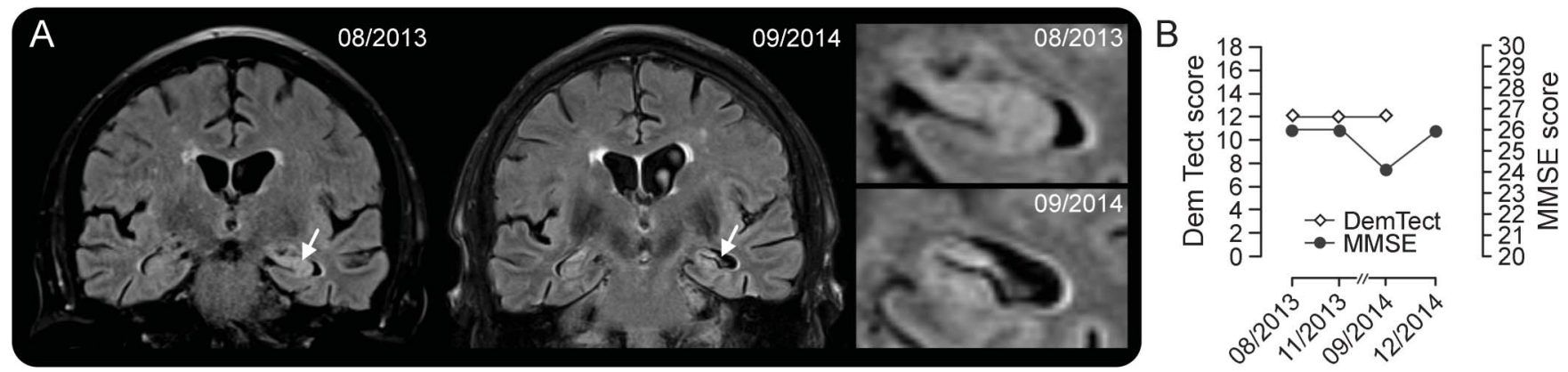

C

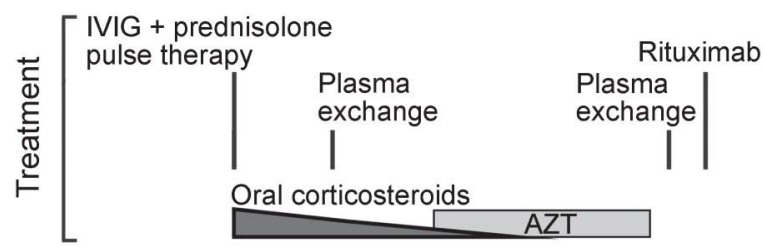

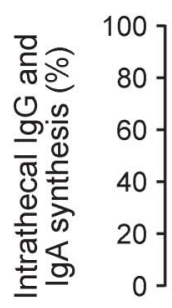

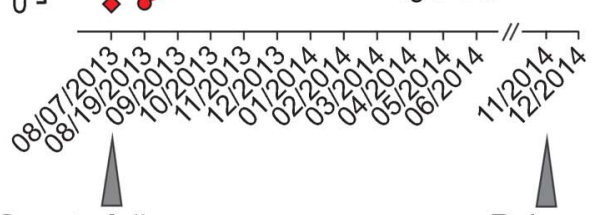

Onset of disease
Relapse
D
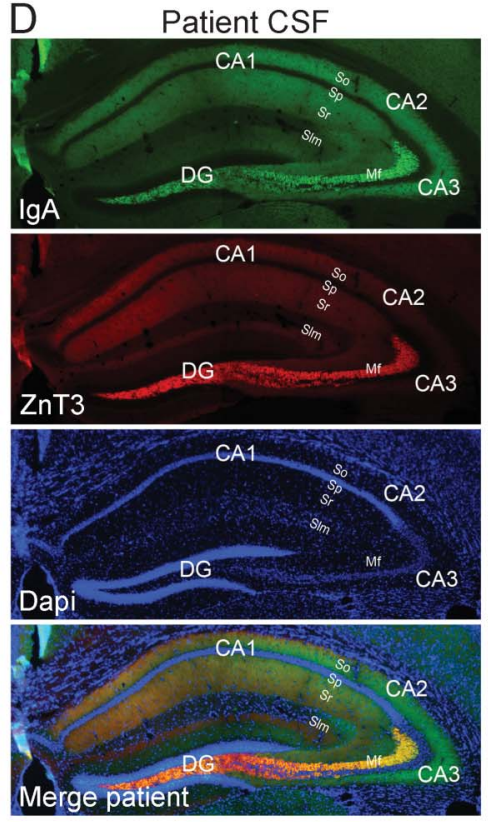

\section{Control CSF}
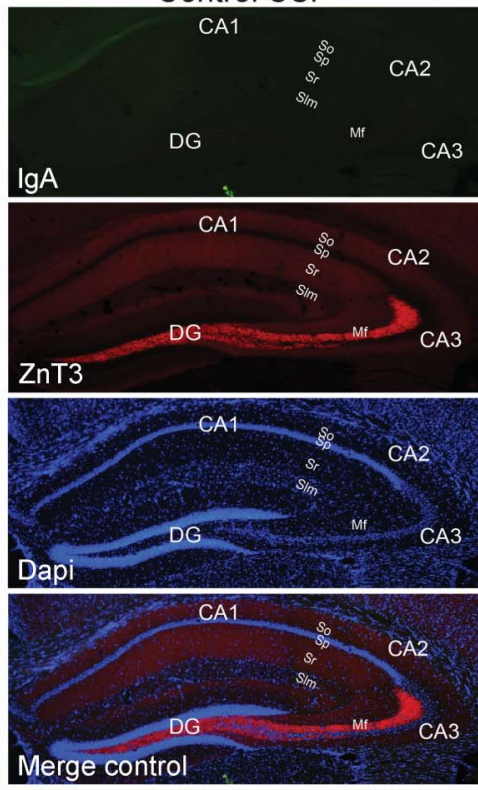

\section{E Patient CSF}

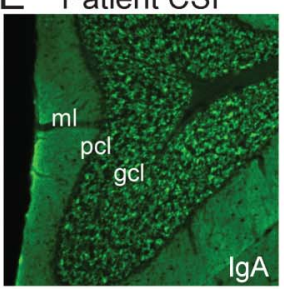

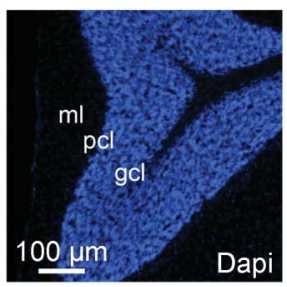

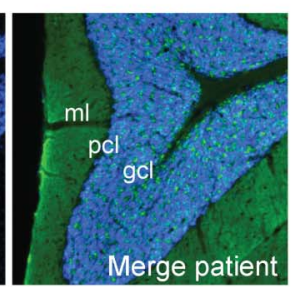

\section{Control CSF}
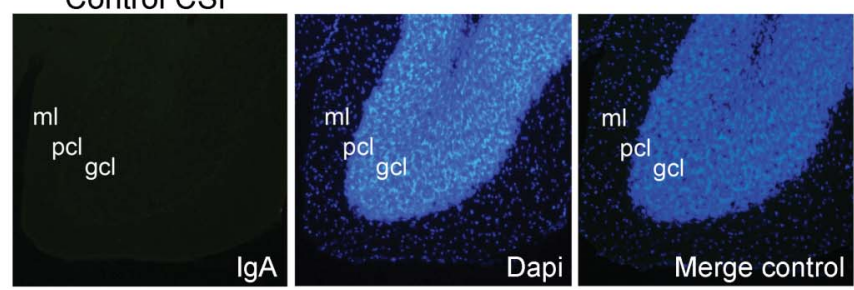

(A) Cranial MRI of a 69-year-old man with limbic encephalitis demonstrates left mesiotemporal signal hyperintensities on coronal fluid-attenuated inversion recovery sequences (arrow, see also enlarged region) at first presentation in August 2013, which progressed into hippocampal atrophy (arrow, see also enlarged region) until September 2014. (B) Repeated cognitive screening by DemTect and Mini-Mental State Examination (MMSE) show mild cognitive impairment. (C) Time course of clinical symptoms, immunotherapies, and calculated percentage of intrathecally synthesized immunoglobulin $A$ (IgA) or immunoglobulin G (IgG) of the total IgA or IgG in CSF. (D) Fixed and permeabilized mouse hippocampus sections were stained with patient CSF at a dilution of 1:100 (left panels) and a FITC-coupled antihuman IgA secondary antibody, demonstrating strong immunoreactivity within the neuropilar regions of the cornu ammonis and dentate gyrus including a prominent signal mapping to the mossy fiber tract. Immunoreactivity of the patient's CSF IgA colocalized with that of ZnT3, a marker of glutamatergic mossy fiber terminals expressed in synaptic vesicles. Control CSF adjusted to the same IgA concentration as the patient's CSF revealed no signal (right panels). Dapi staining was used to visualize nuclei. (E) Mouse cerebellum sections were stained with patient and control CSF as described above, demonstrating binding of patient CSF IgA to the molecular layer and the granule cell layer glomeruli, but not to Purkinje cells. AZT = azathioprine; $\mathrm{CA}=$ cornu ammonis; Dapi $=4$ 4 $^{\prime}, 6$-Diamidin-2-phenylindol; DG $=$ dentate gyrus; gcl $=$ granule cell layer; IVIg = IV immunoglobulin; Mf = mossy fiber tract; $\mathrm{ml}=$ molecular layer; $\mathrm{pcl}=$ Purkinje cell layer; SIm = stratum lacunosum moleculare; So $=$ stratum oriens; $\mathrm{Sp}=$ stratum pyramidale; $\mathrm{Sr}=$ stratum radiatum.

Laboratory methods. Details of the laboratory methods used in this work, including indirect immunofluorescence, immunoprecipitation, mass spectrometry, synapsin knockout mice, cell-based assays, and calculation of antibody indices (AIs) are provided in appendix e-1 at Neurology.org/nn.
RESULTS Case report. In August 2013, a 69-year-old man with a history of a previous seizure in March 2012 presented with confusion, disorientation, and a generalized epileptic seizure. Cerebral MRI revealed signal hyperintensities in the left mesial temporal lobe 
(figure 1A). EEG showed left frontocentral slowing and few epileptiform discharges. Neuropsychological testing revealed mild cognitive impairment (figure 1B). CSF analyses demonstrated a lymphocytic pleocytosis $(22$ cells $/ \mu \mathrm{L})$, elevated protein $(1.43 \mathrm{~g} / \mathrm{L}$, reference $<0.5$ $\mathrm{g} / \mathrm{L}$ ), and CSF-specific oligoclonal IgG bands with $47 \%$ of the total IgG in CSF being synthesized intrathecally (figure 1C). Further CSF examinations additionally revealed a strong intrathecal IgA synthesis, persisting until the last follow-up CSF examination in June 2014.

Virologic and bacteriologic studies were normal. Screening of serum and CSF for known antineuronal antibodies (NMDA receptor, AMPA receptor, GABAB receptor, LGI1, CASPR2, glycine receptor, $\mathrm{Hu}, \mathrm{Ri}$, Yo, $\mathrm{Tr}, \mathrm{Ma} / \mathrm{Ta}$, GAD, amphiphysin, aquaporin-4) using cell-based assays (EUROIMMUN, Lübeck, Germany) as well as testing of serum for antinuclear antibodies and antibodies to gliadin was negative. However, IgG antibodies to voltage-gated potassium channels (VGKC) were detected by radioimmunoprecipitation assay in CSF (17 pmol/L, reference $<2 \mathrm{pmol} / \mathrm{L}$, see appendix $\mathrm{e}-2)$, but not in serum. Intrigued by the patient's strong intrathecal IgA synthesis, we investigated a possible reactivity of IgA in the patient's CSF with fixed and permeabilized mouse hippocampus sections by indirect immunofluorescence. This demonstrated strong binding of IgA in the patient's CSF to the neuropilar regions of the Cornu ammonis and dentate gyrus, including a prominent signal in the mossy fiber tract (figure 1D). Immunoreactivity of the patient's CSF IgA colocalized with that of the zinc transporter ZnT3, a marker of glutamatergic mossy fiber terminals expressed in synaptic vesicles. CSF IgA also stained the amygdala (figure e-1) and the molecular and granular layers, but not Purkinje cells, in mouse cerebellum (figure 1E). No immunoreactivity was observed in mouse brain sections stained with control CSF applied at the same IgA concentration as the patient's CSF (figure 1, D and E).

The patient was diagnosed with limbic encephalitis associated with antineuronal antibodies. Whole-body CT, urologic examination, esophagogastroduodenoscopy, and colonoscopy did not reveal an underlying tumor. Immunotherapies (summarized in figure 1C) were associated with clinical improvement, but MRI revealed progressive left hippocampal atrophy (figure 1A). After a relapse in November 2014, the patient was switched to rituximab. Under this therapy, he is currently asymptomatic except for mild cognitive impairment and has had no further relapses.

Synapsin Ia, Ib, and IIa as target antigens. CSF IgA of the patient, but not of a control, detected proteins between 70 and $100 \mathrm{kDa}$ in immunoblots from mouse brain homogenates. Subcellular fractionation showed enrichment of these proteins in synaptic vesicles (figure 2A).
CSF IgA of the patient, but not of a control, immunoprecipitated the $70-100 \mathrm{kDa}$ proteins (figure $2 \mathrm{~B}$ ), which were subsequently excised from a Coomassie gel (figure 2C) and analyzed by mass spectrometry, demonstrating sequences from both synapsin I and synapsin II (figure 2D).

To confirm the specificity of the patient's antibodies for synapsin and to identify the targeted synapsin isoforms, we carried out immunoblots with brain homogenates from wild-type, synapsin I, synapsin II, or synapsin I/II/III knockout mice (figure $2 \mathrm{E})$. Reactivity of the patient's CSF IgA with synapsin $\mathrm{Ia}, \mathrm{Ib}$, and IIa was abolished in the respective knockout mice, indicating that the patient's antibodies recognize synapsin Ia, Ib, and IIa. While the patient's CSF IgA did not detect synapsin IIb, it reacted with an approximately $80 \mathrm{kDa}$ band in synapsin I/II/III knockout mice, possibly representing an additional autoantigen of unknown identity. Immunohistochemical staining of wild-type mouse brain sections by the patient's CSF IgA was abrogated in synapsin I/II/III knockout tissue (figure 2F).

Cell-based assays (CBAs) with fixed and permeabilized HEK293 cells transfected with synapsin Ia, Ib, IIa, or IIb plasmids further confirmed binding of the patient's CSF IgA to synapsin Ia, Ib, and IIa, but not IIb (figure 3A). Staining of fixed and permeabilized mouse hippocampus sections and fixed and permeabilized primary mouse hippocampal neurons with CSF IgA and commercial anti-synapsin I/II antibodies demonstrated colocalization of both signals (figure 3B).

CSF IgG of the patient likewise reacted with synapsin Ia and Ib, and weakly with synapsin IIa, and colocalized with commercial anti-synapsin I/II antibodies and patient CSF IgA in mouse hippocampus sections (figure e-2). Furthermore, IgA and IgG in the patient's serum reacted with synapsin Ia, Ib, and IIa (figure e-3). Screening of sera of 17 healthy controls demonstrated no IgG antibodies to synapsin Ia (figure e-4). IgA antibodies to synapsin were not determined in the healthy controls.

In contrast to the binding of fixed and permeabilized synapsin-transfected HEK293 cells as well as of fixed and permeabilized primary hippocampal neurons by the patient's CSF, staining of live, unfixed, and nonpermeabilized HEK293 cells transfected with synapsin Ia as well as of live, unfixed, and nonpermeabilized primary mouse hippocampal neurons with CSF IgA and IgG and with commercial anti-synapsin I/II antibodies revealed no immunoreactivity (figure e-5).

Finally, we determined titers of $\operatorname{IgA}$ and $\operatorname{IgG}$ to synapsin Ia and $\mathrm{Ib}$ in all available CSF/serum pairs of our patient using CBAs (appendix e-2). Subsequent calculation of AIs demonstrated strongly elevated $\mathrm{AI}$ values, indicating intrathecal synthesis of IgA and IgG to synapsin Ia and Ib (figure 3C). 


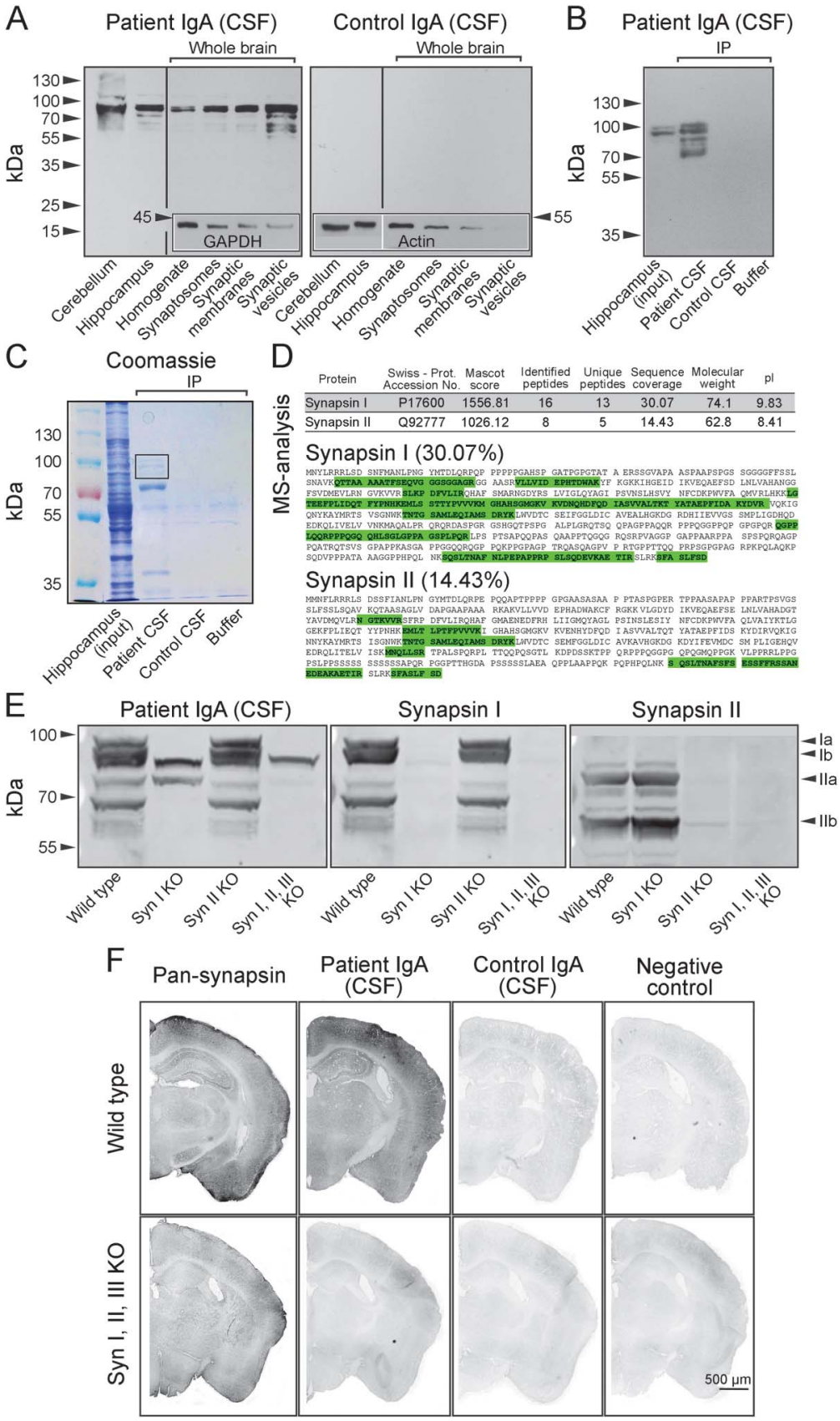

(A) Homogenates of mouse cerebellum and hippocampus as well as subcellular fractions from whole brain progressively enriched for synaptic vesicles (homogenate, synaptosomes, synaptic membranes, synaptic vesicles) were blotted and incubated with patient CSF. Bound immunoglobulin A (lgA) was detected using a peroxidase-labeled antihuman IgA secondary antibody and enhanced chemoluminescence (ECL), demonstrating proteins between 70 and $100 \mathrm{kDa}$ with enrichment in synaptic vesicles. Incubation with control CSF yielded no signals. glyceraldehyde 3-phosphate dehydrogenase (GAPDH) and actin served as loading controls. (B) Mouse hippocampus homogenate was immunoprecipitated with antihuman IgA (heavy chain) agarose beads preincubated with patient CSF. Pelleted beads were blotted and membranes incubated with patient CSF and antihuman lgA to detect the precipitated antigens. ECL detection revealed proteins of 70-100 kDa. Beads preincubated with control CSF or buffer did not precipitate proteins. (C) Coomassie-stained gel of the immunoprecipitated proteins. The boxed area, corresponding to the upper 3 bands seen in lane 2 in (B), was excised from the gel and subjected to mass spectrometry. (D) Mass spectrometry (MS) identified synapsin (Syn) I and Syn II as the 2 proteins with the highest Mascot scores. Amino acid sequences of Syn I and Syn II are shown with the identified peptides highlighted in green. (E) Brain extracts from wild-type, Syn I, Syn II, or Syn I/II/III knockout (KO) mice were blotted and incubated with patient CSF. Bound IgA was detected using a FITC-labeled antihuman IgA secondary antibody. Corresponding membranes were developed with commercial Syn I and Syn II antibodies. Syn la, lb, and Ila bands were abolished in the respective KO mice. Syn Ilb was not detected by the patient's antibodies. An approximately $80 \mathrm{kDa}$ band visible in Syn I/I/III KO mice could represent an additional autoantigen of unknown identity. (F) Brain sections of wild-type and Syn I/II/III KO mice were incubated with a pan-Syn antibody, patient CSF, control CSF, or no primary antibody (negative control) and developed with a FITC-labeled antihuman IgA secondary antibody. Immunoreactivity of patient CSF in wild-type was abrogated in Syn I/II/III KO mice. IP = immunoprecipitation; $\mathrm{pl}=$ isoelectric point. 
Figure 3 Detection of synapsin la, lb, and lla in cell-based assays, colocalization of patient IgA and commercial synapsin antibodies in hippocampus sections and primary hippocampal neurons, and calculation of antibody indices

A

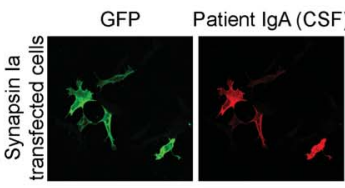

HEK cells
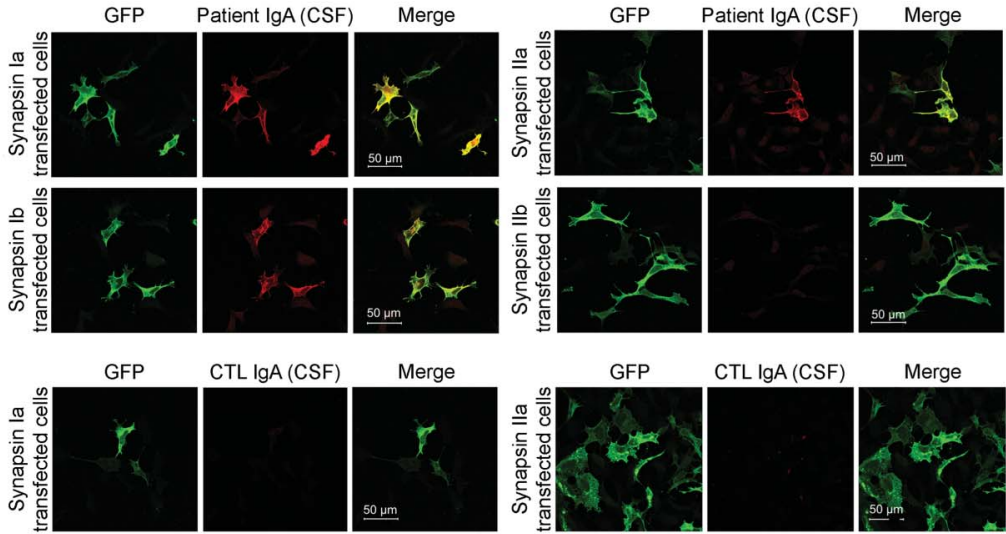

$C T L \operatorname{IgA}(\mathrm{CSF})$
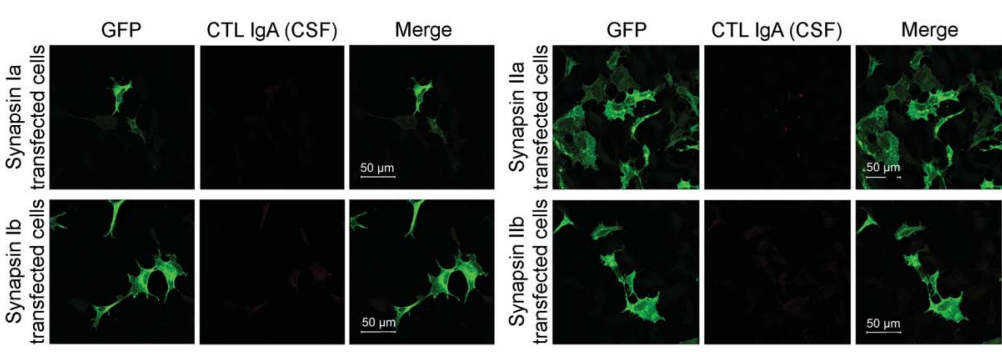

\section{B}
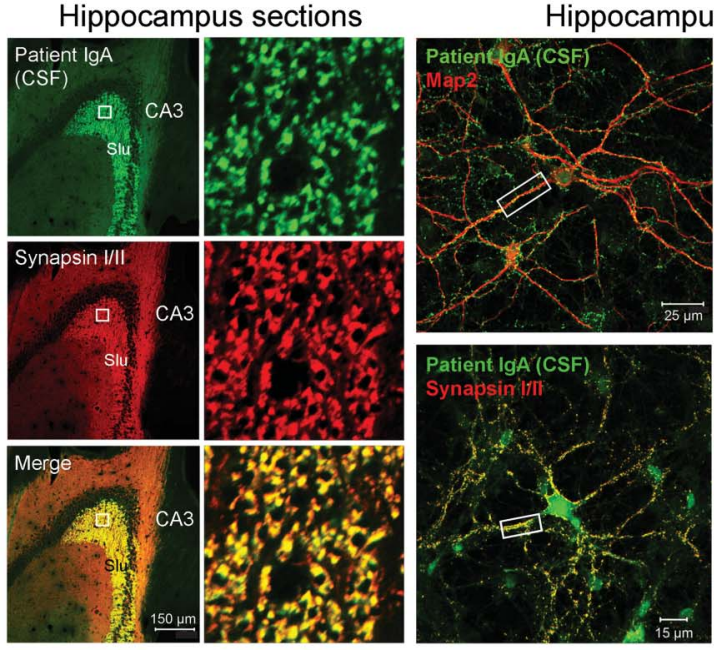

Hippocampus culture

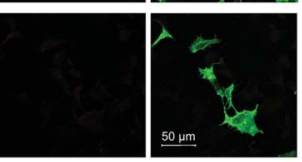

C
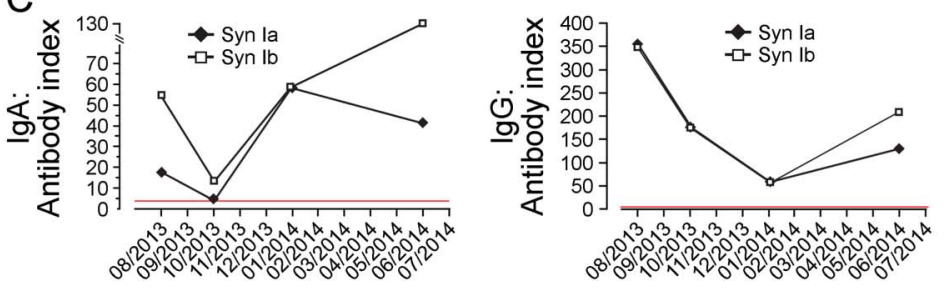

(A) Human embryonal kidney (HEK293) cells transfected with synapsin (Syn) la, lb, lla, or Ilb were fixed, permeabilized, and incubated with patient or control (CTL) CSF. Bound immunoglobulin A (IgA) was detected using an Alexa 594-coupled antihuman IgA secondary antibody. An anti-green fluorescent protein (green fluorescent protein) antibody was used to enhance endogenous fluorescence of transfected cells. CSF IgA-stained cells expressing Syn la, lb, and Ila, but not llb. Cells incubated with control CSF showed no staining. (B) Left: Murine hippocampus sections were fixed, permeabilized, and incubated with patient CSF (dilution 1:100) and double-stained with a commercial antibody to both Syn I and Syn II, demonstrating colocalization of patient IgA and Syn I/II antibodies at the mossy fiber terminals in the stratum lucidum (Slu) of the CA3 region (boxed regions are depicted at higher magnification). Right: Staining of primary fixed and permeabilized murine hippocampal neurons with patient CSF and antibodies to microtubule-associated protein 2, a somatodendritic marker, showed a punctuate staining of CSF IgA along dendrites, indicative of a synaptic distribution. Double-staining of hippocampal neurons with patient CSF IgA and antibodies to Syn I/II revealed a complete overlap of signals. (C) IgA and immunoglobulin G (lgG) antibodies to Syn la/lb in CSF and serum were titrated using cell-based assays and antibody indices were calculated as described in the Methods. The red line indicates the cutoff of 4, Al values above which indicate an intrathecal antibody synthesis. There was a strong intrathecal synthesis of $\lg A$ and $\lg G$ to Syn la/lb throughout the course of the disease. $\mathrm{CA}=$ cornu ammonis; Map2 = microtubule-associated protein 2. 
DISCUSSION We report the identification of synap$\sin \mathrm{Ia}, \mathrm{Ib}$, and IIa as autoantigenic targets of intrathecally synthesized IgA and IgG in a patient with clinically and radiologically typical limbic encephalitis. This is based on (1) immunoprecipitation of synapsin from mouse brain homogenates by CSF IgA, (2) abrogation of immunoreactivity to synapsin Ia, $\mathrm{Ib}$, and IIa in synapsin knockout mice, (3) detection of synapsin Ia, Ib, and IIa by the patient's antibodies in CBAs, and (4) colocalization of the patient's antibodies with commercial synapsin I/II antibodies in mouse hippocampus sections and primary neurons.

The intrathecal synthesis of synapsin IgA is a remarkable feature of our patient. The majority of known antineuronal antibodies are $\operatorname{IgG}$ isotypes and a possible role for antineuronal IgA has only rarely been proposed. ${ }^{2}$ We herein identify a neuronal autoantigen using immunoprecipitation with CSF IgA. However, although our results suggest that, besides IgG, also IgA could be relevant in some cases of antineuronal autoimmunity, the significance of synapsin IgA (and IgG) currently remains elusive.

Synapsin isoforms are synaptic vesicle-associated phosphoproteins implicated in neural development and synaptic plasticity. ${ }^{3}$ Antibodies to synapsin I were previously identified in serum of a patient with discoid lupus erythematosus, but these antibodies only reacted with denatured synapsin in immunoblots and did not bind to frozen rat brain section or synapsin-transfected cells. ${ }^{4}$ In contrast, in addition to the detection of denatured synapsin in immunoblots, our patient's antibodies also recognized conformational synapsin in tissue section and CBAs, strongly suggesting that the previously identified antibodies to synapsin and the anti-synapsin antibodies of our patient target different epitopes. Likewise, the fact that our patient's antibodies detect conformational synapsin indicates a higher likelihood of binding to the target in vivo. Anti-gliadin antibodies, previously shown to cross-react with synapsin I and potentially explaining neurologic deficits associated with celiac disease, ${ }^{5}$ were not detected in our patient, excluding such cross-reactivity.

We identified antibodies to synapsin in only a single patient so far and did not detect antibodies to synapsin in sera of 17 healthy controls. Therefore, it is currently impossible to draw any definite conclusions on the syndrome or disease specificity and the prevalence of antibodies to synapsin. We also cannot rule out the possibility that antibodies to synapsin may be an epiphenomenon, e.g., secondary to cell damage. Furthermore, the concomitant presence of antibodies to VGKC and synapsin in the patient's CSF raises the question which autoimmunity may be relevant for the clinical phenotype. However, while VGKC antibodies became undetectable in CSF (appendix e-2), intrathecal synapsin antibody synthesis persisted throughout the course of disease. Lack of synapsin I or synapsin II in mice triggers epileptic seizures ${ }^{6}$ and mild cognitive impairment ${ }^{7}$ and mutations in the gene encoding synapsin I are associated with epilepsy, ${ }^{8,9}$ compatible with the idea that genetic as well as autoimmune ablations of synapsins could result in a similar clinical phenotype.

The absence of staining of live, unfixed, and nonpermeabilized HEK293 cells transfected with synapsin Ia as well as of live, unfixed, and nonpermeabilized primary mouse hippocampal neurons with our patient's CSF IgA and IgG as well as commercial anti-synapsin I/II antibodies was an expected result consistent with the known intracellular expression of synapsin on the cytoplasmic surface of synaptic vesicles. ${ }^{3}$ This intracellular expression of synapsin questions the accessibility for autoantibodies and thus their potential pathogenic relevance. Nevertheless, under conditions of high neuronal activity or oxidative stress, synapsin can be extracellularly released from glial-derived exosomes, thereby promoting neurite outgrowth and neuronal survival through modulation of interactions between glia and neurons. ${ }^{10}$ Hypothetically, such released synapsin could be accessible for anti-synapsin IgA and IgG.

Altogether, though formal proof is lacking, a potential pathogenic role of synapsin antibodies appears conceivable and possible pathogenic mechanisms of anti-synapsin antibodies should be further investigated. Future studies should also clarify the prevalence of antibodies to synapsin in patients with limbic encephalitis, other neurologic diseases, and the general population.

\section{AUTHOR CONTRIBUTIONS}

J.P., M.H., F.B., D.G., A.P., G.A.-H., and K.R. designed the study and analyzed data. C.O., H.H., J.P., and K.R. collected and interpreted clinical data. J.P., M.H., F.B., D.G., A.P., A.M., F.C., and J.-F.Z. carried out experiments. K.R., G.A.-H., J.P., and M.H. drafted the manuscript, which was revised, edited, and finally approved by all authors.

\section{ACKNOWLEDGMENT}

The authors thank Antje Dräger for technical assistance.

\section{STUDY FUNDING}

No targeted funding.

\section{DISCLOSURE}

J. Piepgras, M. Höltje, C. Otto, H. Harms, and A. Satapathy report no disclosures. F. Cesca received research support from Ministry of Education, University and Research, Ministry of Health, Compagnia di San Paolo. F. Befenati reports no disclosures. D. Gitler received research support from Israel Science Foundation. A. Pich, J.-F. Zander, and G. Ahnert-Hilger report no disclosures. K. Ruprecht is on scientific advisory boards for Sanofi-Aventis/Genzyme, Novartis, and Roche, received travel funding and/or speaker honoraria from Bayer Healthcare, Biogen Idec, Merck Serono, Sanofi-Aventis/Genzyme, Teva Pharmaceuticals, Novartis, and Guthy Jackson Charitable Foundation, is an academic editor for PLOS One, receives publishing royalties from Elsevier, and received research support from Novartis and the German Ministry of Education and Research. Go to Neurology.org/nn for full disclosure forms.

Received May 25, 2015. Accepted in final form August 25, 2015. 


\section{REFERENCES}

1. Leypoldt F, Armangue T, Dalmau J. Autoimmune encephalopathies. Ann NY Acad Sci 2015;1338:94-114.

2. Prüss H, Höltje M, Maier N, et al. IgA NMDA receptor antibodies are markers of synaptic immunity in slow cognitive impairment. Neurology 2012;78:1743-1753.

3. Cesca F, Baldelli P, Valtorta F, Benfenati F. The synapsins: key actors of synapse function and plasticity. Prog Neurobiol 2010;91:313-348.

4. Gitlits VM, Sentry JW, Matthew LS, Smith AI, Toh BH. Synapsin I identified as a novel brain-specific autoantigen. J Investig Med 2001;49:276-283.

5. Alaedini A, Okamoto $\mathrm{H}$, Briani C, et al. Immune crossreactivity in celiac disease: anti-gliadin antibodies bind to neuronal synapsin I. J Immunol 2007;178:6590-6595.

6. Rosahl TW, Spillane D, Missler M, et al. Essential functions of synapsins I and II in synaptic vesicle regulation. Nature 1995;375:488-493.
7. Corradi A, Zanardi A, Giacomini C, et al. Synapsin-Iand synapsin-II-null mice display an increased agedependent cognitive impairment. J Cell Sci 2008;121: 3042-3051.

8. Garcia CC, Blair HJ, Seager M, et al. Identification of a mutation in synapsin I, a synaptic vesicle protein, in a family with epilepsy. J Med Genet 2004;41: 183-186.

9. Fassio A, Patry L, Congia S, et al. SYN1 loss-offunction mutations in autism and partial epilepsy cause impaired synaptic function. Hum Mol Genet 2011;20: 2297-2307.

10. Wang S, Cesca F, Loers G, et al. Synapsin I is an oligomannose-carrying glycoprotein, acts as an oligomannose-binding lectin, and promotes neurite outgrowth and neuronal survival when released via glia-derived exosomes. J Neurosci 2011;31:72757290. 


\section{Neurology \\ Neuroimmunology \& Neuroinflammation}

\section{Intrathecal immunoglobulin $A$ and $G$ antibodies to synapsin in a patient with limbic encephalitis}

Johannes Piepgras, Markus Höltje, Carolin Otto, et al.

Neurol Neuroimmunol Neuroinflamm 2015;2;

DOI 10.1212/NXI.0000000000000169

This information is current as of November 4, 2015

Updated Information \&

Services

Supplementary Material

References

Subspecialty Collections

Permissions \& Licensing

Reprints including high resolution figures, can be found at:

http://nn.neurology.org/content/2/6/e169.full.html

Supplementary material can be found at:

http://nn.neurology.org/content/suppl/2015/11/04/2.6.e169.DC1

This article cites 10 articles, 4 of which you can access for free at: http://nn.neurology.org/content/2/6/e169.full.html\#\#ref-list-1

This article, along with others on similar topics, appears in the following collection(s):

All Cognitive Disorders/Dementia

http://nn.neurology.org//cgi/collection/all_cognitive_disorders_dementi

a

Autoimmune diseases

http://nn.neurology.org//cgi/collection/autoimmune_diseases

Encephalitis

http://nn.neurology.org//cgi/collection/encephalitis

Information about reproducing this article in parts (figures,tables) or in its entirety can be found online at:

http://nn.neurology.org/misc/about.xhtml\#permissions

Information about ordering reprints can be found online:

http://nn.neurology.org/misc/addir.xhtml\#reprintsus

Neurol Neuroimmunol Neuroinflamm is an official journal of the American Academy of Neurology.

Published since April 2014, it is an open-access, online-only, continuous publication journal. Copyright $\odot$ 2015 American Academy of Neurology. All rights reserved. Online ISSN: 2332-7812.

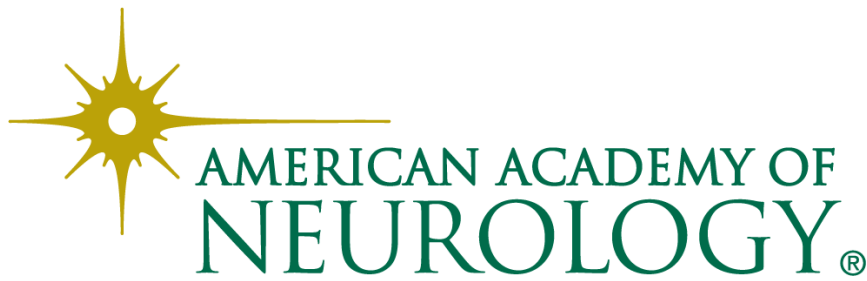

